\title{
Disruption of the CCL1-CCR8 axis inhibits vascular Treg recruitment and function and promotes atherosclerosis in mice
}

Marian Vila-Caballer ${ }^{\mathrm{a}, \mathrm{b}, \dagger}$, José M. González-Granado,d,e,f,, , Virginia Zorita ${ }^{\mathrm{c}}$, Yafa N Abu Nabah $^{\mathrm{a}}$, Carlos Silvestre-Roig ${ }^{\mathrm{c}, \mathrm{g}}$, Alberto del Monte-Monge ${ }^{\mathrm{c}, \mathrm{d}}$, Pedro Molina-Sánchez ${ }^{\mathrm{c}}$, Hafid Ait-Oufella $^{\mathrm{h}}$, María J. Andrés-Manzano ${ }^{c, d}$, María J. Sanz ${ }^{\mathrm{i}}$, Christian Weber ${ }^{\mathrm{g}}$, Leonor Kremer ${ }^{\mathrm{j}}$, Julio Gutiérrez ${ }^{\mathrm{j}}$, Ziad Mallat ${ }^{\mathrm{h}, \mathrm{k}}$, Vicente Andrés ${ }^{\mathrm{c}, \mathrm{d}, *}$

a Instituto de Biomedicina de Valencia (IBV-CSIC), Valencia, Spain

${ }^{\mathrm{b}}$ Universidad Cardenal Herrera-CEU (CEU Universities), Valencia, Spain

${ }^{\mathrm{c}}$ Centro Nacional de Investigaciones Cardiovasculares (CNIC), Madrid, Spain

${ }^{\mathrm{d}}$ CIBER de Enfermedades Cardiovasculares (CIBER-CV), Spain

${ }^{\mathrm{e}}$ LamImSys Laboratory, Instituto de Investigación Sanitaria Hospital 12 de Octubre (imas12), Madrid, Spain

${ }^{\mathrm{f}}$ Departamento de Fisiología. Facultad de Medicina. Universidad Autónoma de Madrid (UAM).

${ }^{g}$ Institute for Cardiovascular Prevention (IPEK), Ludwig Maximilian University, Munich, Germany

${ }^{\text {h }}$ Institut National de la Santé et de la Recherche Médicale (INSERM), Paris Cardiovascular Research Center, France

i Departamento de Farmacología, Universidad de Valencia and Instituto de Investigación Sanitaria-INCLIVA, Valencia, Spain-INCLIVA, Valencia, Spain

${ }^{j}$ Departamento de Inmunología y Oncología, Centro Nacional de Biotecnología-CSIC, Madrid, Spain

${ }^{\mathrm{k}}$ Division of Cardiovascular Medicine, University of Cambridge, UK

$\dagger$ These authors contributed equally

*Corresponding author: Vicente Andrés (vandres@ cnic.es)

Current address:

P. Molina: The Tisch Cancer Institute at Mount Sinai, New York, USA

\section{Short tittle:}

CCL1-CCR8 inhibition aggravates atherosclerosis 


\begin{abstract}
The CC chemokine 1 (CCL1, also called I-309 or TCA3) is a potent chemoattractant for leukocytes that plays an important role in inflammatory processes and diseases through binding to its receptor CCR8. Here, we investigated the role of the CCL1-CCR8 axis in atherosclerosis. We found increased expression of CCL1 in the aortas of atherosclerosis-prone fat-fed apolipoprotein E (Apoe)-null mice; moreover, in vitro flow chamber assays and in vivo intravital microscopy demonstrated an essential role for CCL1 in leukocyte recruitment. Mice doubly deficient for CCL1 and Apoe exhibited enhanced atherosclerosis in aorta, which was associated with reduced plasma levels of the anti-inflammatory interleukin 10, an increased splenocyte Th1/Th2 ratio, and a reduced regulatory $\mathrm{T}$ cell (Treg) content in aorta and spleen. Reduced Treg recruitment and aggravated atherosclerosis were also detected in the aortas of fat-fed lowdensity lipoprotein receptor-null mice treated with CCR8 blocking antibodies. These findings demonstrate that disruption of the CCL1-CCR8 axis promotes atherosclerosis by inhibiting interleukin 10 production and Treg recruitment and function.
\end{abstract}

Keywords: Atherosclerosis; CCL1; CCR8; Treg; IL-10

\title{
Highlights
}

- CCL1 ablation impairs vascular Treg recruitment and function

- CCL1 ablation is associated with reduced IL-10 production, impaired Th2 response, and increased Th1 response

- Inactivation of CCL1-CCR8 axis aggravates atherosclerosis development 


\section{Abbreviations:}

Apoe: apolipoprotein E

Apoe-KO: apolipoprotein E-null mice

Apoe/Ccl1-DKO: apolipoprotein E-CCL1 doubly-deficient mice

BMdM: bone marrow-derived macrophage

CCL1: CC chemokine 1 (also named TCA3 and I-309)

CCR8: chemokine (C-C motif) receptor 8

HFD: high-fat diet

IL-10: interleukin 10

Ldlr-KO: low-density lipoprotein receptor-null mice

RFP: red fluorescent protein

Th: helper $\mathrm{T}$ cell

Treg: regulatory $\mathrm{T}$ cell

VSMC: vascular smooth muscle cell 


\section{Introduction}

Atherosclerotic disease is the main cause of mortality worldwide $[1,2]$. The disease features a robust inflammatory component that is characterized by lipid deposition and leukocyte recruitment in the artery wall during all disease phases [3]. The initiation and progression of atherosclerosis both involve chronic inflammatory responses to lipoprotein deposition in the arterial intima. These inflammatory responses are caused by activation of both innate and adaptive immunity $[4,5]$. The innate immune response is triggered by the accumulation of certain lipid and protein components of apoB lipoproteins, which cause an inflammatory reaction that activates endothelial cells and stimulates the entry of bone-marrow-derived monocytes into the intima. Intimal Ly6 $\mathrm{C}^{\mathrm{hi}}$ monocytes differentiate into macrophages that acquire an inflammatory phenotype, which promotes atherosclerosis development $[4,5]$. The adaptive immune response involves CD4+ $\mathrm{T}$ cells, which have been shown to promote atherosclerosis in fat-fed mice [6]. When naïve CD4+ T cells are activated after the recognition of an antigen presented by dendritic cells, they undergo a process of division and differentiation into several helper T (Th) cell subsets, including Th1, Th2, Th17, and regulatory T cells (Tregs) [7]. Several studies have shown that Th1 responses are pro-atherogenic in mice [8-11], contrasting with the atheroprotective effect of Tregs [12,13]. Regarding anti-inflammatory cytokines, both interleukin-10 (IL-10) $[14,15]$ and transforming growth factor- $\beta[16,17]$ have been shown to protect against atherosclerosis in mice.

Chemokines are key mediators of cell trafficking [18-20]. The chemokine (C-C) motif receptor 8 (CCR8) ligand CC chemokine 1 (CCL1, also called TCA3 and I-309) was initially described as a cytokine expressed by activated T lymphocytes [21]. CCL1 acts as a potent chemoattractant for monocytes and lymphocytes [22] and has been proposed to contribute to macrophage and lymphocyte recruitment and activation [23] in several inflammatory diseases, including type 1 diabetes [24], atopic asthma [25], atopic dermatitis [26, 27], Kaposi sarcoma [28], septic peritonitis [29], liver fibrosis [30], and experimental autoimmune encephalomyelitis [31]. In addition, CCL1 may be involved in immune homeostasis, particularly through effects on Tregs [32]. In the context of the cardiovascular system, CCL1 is expressed in endothelial cells, macrophages, and the extracellular area of human atherosclerotic plaques [33]; moreover, CCL1 stimulates vascular smooth muscle cell (VSMC) migration [28] and activates endothelial cells in response to arterial wall injury [34]. However, the role of CCL1 in atherosclerosis remains unknown.

In the present study, we investigated whether the CCL1-CCR8 axis plays a role in mouse atherosclerosis. To this end, we generated atherosclerosis-prone mice deficient for CCL1 by crossing Ccll-null mice with apolipoprotein E-null mice (Apoe-KO). Our results show that disruption of the CCL1-CCR8 axis impairs vascular Treg recruitment and function and promotes atherosclerosis. 


\section{Materials and methods}

2.1. Mice and diets. Wild-type mice, Apoe-KO mice, and LDL receptor-null mice ( $L d l r-\mathrm{KO}$, CD45.1 genotype) were obtained from Charles River Laboratories (Wilmington, Massachusetts, USA). Transgenic Foxp3-mRFP mice expressing red fluorescent protein in Tregs were a gift from Dr. Richard A. Flavell (Yale University School of Medicine, New Haven, Connecticut, USA) [35]. Ccll-KO [36] and Apoe-KO mice were crossbred to generate Apoe/Ccl1-DKO mice. All mice were on a C57BL/6J genetic background. Mice for the flow chamber and intravital experiments were males. All other experiments were performed using littermates of both genders. After weaning, mice were maintained on a low-fat (control) standard diet (2.8\% fat; Panlab, Barcelona, Spain) or placed on pro-atherogenic high-fat diet (HFD) for the indicated periods, starting at 2 months of age (10.8\% total fat, $0.75 \%$ cholesterol, S4892-E010, Ssniff, Soest, Germany). Animal experiments were approved by the local ethics committee and the Spanish Ministry of Agriculture and Fisheries, Food and Environment. All animal procedures conformed to EU Directive 86/609/EEC and Recommendation 2007/526/EC regarding the protection of animals used for experimental and other scientific purposes, enforced in Spanish law under Real Decreto 1201/2005.

2.2. Ccl1 mRNA expression studies. Femoral bone marrow-derived macrophages (BMdMs) and aortic VSMCs cultures were obtained from Apoe-KO mice as previously described [37]. Cultures were maintained at $37{ }^{\circ} \mathrm{C}$ in a humidified $5 \% \mathrm{CO}_{2}$ atmosphere with DMEM/10\% FBS $/ 10 \%$ macrophage-colony stimulating factor medium for BMdMs, and $20 \%$ FBS/DMEM/Fungizone medium for VSMCs. VSMC cultures were not used above passage 7, and purity was confirmed by immunohistochemistry with anti-SM $\alpha$-actin monoclonal alkaline phosphatase conjugated antibody (1/20 dilution, clone 1A4, a-5691, Sigma, San Luis, Missouri, USA) and Fast Red substrate (Sigma). BMdMs and VSMCs were stimulated for 20 hours with tumor necrosis factor $\alpha$ (TNF $\alpha, 10$ or $50 \mathrm{ng} / \mathrm{ml}$, Sigma), interferon $\gamma$ (IFN $\gamma, 20$ or $200 \mathrm{U} / \mathrm{ml}$, Peprotech, Rocky Hill, NJ, USA), or angiotensin II (AngII, $10^{-6}$ or $10^{-5} \mathrm{M}$, Calbiochem, Merck KGaA, Darmstadt, Germany) (all of mouse origin).

Total RNA was isolated from cultured cells and mouse aortas using TRIzol (Invitrogen, Carlsbad, California, USA). RNA purity and concentration were determined from the A260/280 ratio. cDNA was obtained by reverse transcription using Superscript III First Strand Synthesis Supermix (Invitrogen). Complementary DNA was amplified in TaqMan gene Expression Assays (TaqMan MGB probes, FAM ${ }^{\mathrm{TM}}$ dye-labeled): Mm00441236 (Ccl1), Mm99999115 (Ccr8), and Mm00607939 (using $\beta$-actin as endogenous control). The relative $C c l 1$ expression level was calculated from technical triplicates for each sample using the $2^{-\Delta \Delta \mathrm{Ct}}$ formula and were expressed relative to Apoe- $K O$ mice fed the control diet.

The RT-qPCR primer sequences were as follows:

Mouse RFP-FW: 5'-ACTACAAGAAGCTGTCCTTCC-3'

Mouse RFP-RV: 5'-ATGTTTAAACTTACCCTCCCAG-3' 
Mouse $\beta$-actin-FW: 5'-GACGGCCAGGTCATCACTATTG-3'

Mouse $\beta$-actin-RV: 5'-AGGAAGGCTGGAAAAGAGCC-3'.

2.3. Metabolic measurements and circulating leukocyte analysis. Mouse blood was collected in EDTA tubes. For circulating lipid measurements (total cholesterol, HDL-cholesterol, and triglycerides), mice were fasted overnight and plasma was obtained by blood centrifugation. Lipids were measured using enzymatic procedures (WAKO, Richmond, VA, USA). HDLcholesterol was determined after precipitation of the apoB-containing lipoproteins with dextran-sulphate/ $\mathrm{MgCl}_{2}$ (Sigma) [38].

Following lysis of erythrocytes, circulating T-cells (CD3+), B-cells (CD19+), and monocytes/granulocytes $(\mathrm{CD} 11 \mathrm{~b}+)$ were analyzed by flow cytometry after leukocytes were stained for rat anti-mouse cd11b-FITC IgG2b monoclonal antibody (1/100 dilution, clone M1/70, 557396, Becton Dickinson, Franklin Lakes, New Jersey, USA), hamster anti-mouse CD3e chain-PE-Cy7 monoclonal antibody (1/10 dilution, clone 145-2C11, 552774, Becton Dickinson), and rat anti-mouse CD19-FITC IgG2a monoclonal antibody (1/25 dilution, clone 6D5, MCA1439F, Serotec, Dusseldorf, Germany). Monocytes were distinguished from granulocytes by their granular content as reflected in low/high side scatter (SSC) [39].

\subsection{Quantification of atherosclerosis burden and immunohistochemical characterization of} atherosclerotic lesions. All studies were performed by an investigator blinded to genotype. Atherosclerosis was quantified in Apoe-KO and Apoe/Ccll-DKO mice fed HFD for 2 months, and in $\gamma$-irradiated and bone marrow-transplanted $L d l r-K O$ mice fed HFD for 1 week. Aortic tissue was embedded in paraffin and cut into 5- $\mu \mathrm{m}$ cross-sections. The extent of atherosclerosis was calculated as the intimal area in the aortic root and ascending aorta as previously described [37]. Five cross-sections separated 8-12 $\mu \mathrm{m}$ were analysed in each region. The distance between sections in the aortic root and ascending aorta was approximately $70 \mu \mathrm{m}$.

Immunohistopathological examination of atheromas included the quantification of VSMCs, collagen, necrotic core, T lymphocytes, CCR8-immunoreactive cells, macrophages, proliferating cells, and apoptotic cells (see below). The content of lymphocytes and proliferating cells was expressed as cells $/ \mathrm{mm}^{2}$, whereas the content of VSMCs, collagen, necrotic core, CCR8-expressing cells and macrophages was expressed as both percentage (stained area normalized by total plaque area) and absolute content $\left(\mathrm{mm}^{2}\right.$ of plaque area stained for each marker).

VSMCs were identified with alkaline-phosphatase-conjugated mouse anti-SM $\alpha$-actin monoclonal antibody (1/20 dilution, clone 1A4, a-5691, Sigma) and Fast Red substrate (Sigma). Collagen was identified with Masson's trichrome stain. Necrotic cores were identified as hollows formed in preparations as a consequence of the deparaffinization protocol. $\mathrm{T}$ lymphocytes were identified with biotin-conjugated anti-CD4 antibody $(0.5 \mathrm{mg} / \mathrm{ml}$, clone L3T3, BD-PharMingen) and streptavidin-conjugated Alexa-fluor 488 (1/300 dilution, S11223, Invitrogen) and were mounted after nuclear counterstaining using Topro-3 (1/1000 dilution, T3605, Invitrogen). CCR8+ area was identified with goat anti-CCR8 polyclonal antibody (1/200 dilution, ab1663, Abcam, Cambridge, United Kingdom). Macrophages were identified with rat anti-Mac3 monoclonal antibody (1/200 dilution, clone M3/84, sc-19991, Santa Cruz Biotechnology). Specimens were counterstained with hematoxylin. Proliferating cells were 
identified with rabbit anti-Ki67 monoclonal antibody (prediluted, clone SP6, MAD-000319QD Master Diagnóstica, Granada, Spain) and apoptotic cells with rabbit anti-cleaved Caspase3 (Asp175) polyclonal antibody (1/10 dilution, 9661, Cell signalling, Danvers, Massachusetts, USA).

After incubation with primary antibodies and extensive washes, specimens were incubated with appropriate HRP-conjugated secondary antibodies: goat anti-rat-HRP (sc-2006) for Mac3, donkey anti-goat-HRP (sc-2042) for CCR8 and goat anti-rabbit-HRP (sc-2004) for Ki67 and Caspase 3 (all from Santa Cruz Biotechnology, 1/300 dilution). Immunocomplexes were detected using streptavidin-HRP (TS-060-HR, Lab vision Corporation, USA) and DAB substrate (BUF021A, AbD Serotec). Images were captured with an Olympus CAMEDIAC5060 wide zoom digital camera mounted on a stereomicroscope Axiolab (Carl Zeiss, Jena, Germany) except for $\mathrm{T}$ lymphocyte immunofluorescence, which was visualized with a TCS/SP2 confocal microscope (Leica Microsystems, Wetzlar, Germany). All images were analyzed by computer-assisted morphometric analysis using Metamorph software (Molecular Devices, California, USA).

2.5. Flow chamber. Whole blood was collected from 5-month-old wild-type male mice (pooled from 6-8 mice for each replicate) and perfused in flow chambers containing vehicle-coated or CCL1-coated coverslips. For coating, cover slips (Corning incorporation, Sigma) were coated with soluble mouse recombinant CCL1/TCA3 (5 mg/ml, R\&D systems, Minneapolis, USA) and incubated at $4^{\circ} \mathrm{C}$ for 18 hours. To inhibit non-specific interactions with polystyrene, cover slips were previously incubated with $1 \%$ bovine serum albumin (Sigma) at $37^{\circ} \mathrm{C}$ for 1 hour. Subsequently, vehicle- and CCL1-coated cover slips were perfused with whole blood (diluted 10fold and maintained at $37^{\circ} \mathrm{C}$ ) for 5 minutes at a constant shear rate of $0.75 \mathrm{dynes} / \mathrm{cm}^{2}$, followed by perfusion for 20 minutes with Hanks' balanced salt solution (HBSS). The Glycotech flow chamber was assembled, and 10 random fields of interacting leukocytes were visualized and recorded on the CCL1-coated cover slip surface (x20 objective, $\mathrm{x} 10$ eyepiece) b phase contrast microscopy.

2.6. Intravital microscopy in cremaster muscle. Male wild-type, Apoe-KO, and Apoe/Ccll-DKO mice (approximately 24 weeks old) fed the HFD for 1 week were anesthetized by intraperitonal injection with a mixture of xylazine hydrochloride $(10 \mathrm{mg} / \mathrm{kg}$ ) and ketamine hydrochloride (200 $\mathrm{mg} / \mathrm{kg}$ ). A polyethylene catheter was placed in the jugular vein to permit intravenous administration of additional anesthetic if needed. The cremaster muscle was dissected free of tissues and exteriorized onto an optical clear viewing pedestal. The muscle was cut longitudinally with a cautery and held flat against the pedestal by attaching silk sutures to the corners of the tissue. The muscle was then perfused continuously at a rate of $1 \mathrm{ml} / \mathrm{min}$ with warmed bicarbonatebuffered saline ( $\mathrm{pH}$ 7.4). The cremasteric microcirculation was then observed using an intravital microscope (Nikon Optiphot-2, SMZ1, Badhoevedorp, Netherlands) equipped with a 50x objective (Nikon SLDW, Badhoevedorp, The Netherlands) and a 10x eyepiece. A video camera (Sony SSC-C350P, Koeln, Germany) mounted on the microscope projected the image onto a color monitor and the images were video recorded for playback analysis and quantified as described [40]. 
2.7. Proliferation assays. CD4+ T cells, CD4+CD25+ Tregs and CD4+CD25- effector T cells were purified from spleens using magnetic cell separation (Miltenyi Biotech) as previously described [12]. To analyze $\mathrm{T}$ cell proliferation, CD4+ cells $\left(1 \times 10^{5}\right.$ cells/well) were co-cultured for $72 \mathrm{~h}$ at $37^{\circ} \mathrm{C}$ with $10^{4} \mathrm{CD} 11 \mathrm{c}+$ dendritic cells and soluble anti-CD3 $(1 \mu \mathrm{g} / \mathrm{ml})$. Cells were pulsed with $\left[{ }^{3} \mathrm{H}\right]$-thymidine for the last $18 \mathrm{~h}(1 \mu \mathrm{Ci} /$ well, Amersham, Little Chalfont, United Kingdom). Thymidine incorporation was assessed using a TopCount NXT scintillation counter (Perkin Elmer, Waltham, Massachusetts, USA).

To analyze Treg functions, effector $\mathrm{T}$ cells were cultured alone or co-cultured with purified Tregs (at 1:8, 1:4, 1:2 or 1:1 ratio) in round-bottom 96-well microplates $\left(0.5 \times 10^{5}\right.$ cells/well; total volume $200 \mu 1 /$ well). Cells were stimulated with purified soluble CD3-specific antibody ( $1 \mu \mathrm{g} / \mathrm{ml}, \mathrm{BD}$-PharMingen) in the presence of antigen-presenting cells purified on $\mathrm{CD} 11 \mathrm{c}$-coated magnetic beads (Miltenyi Biotech). Cells were cultured at $37^{\circ} \mathrm{C}$ for $72 \mathrm{~h}$ and pulsed with $\left[{ }^{3} \mathrm{H}\right]$ thymidine for the last $18 \mathrm{~h}(1 \mu \mathrm{Ci} /$ well, Amersham $)$. Thymidine incorporation was assessed using a TopCount NXT scintillation counter (Perkin Elmer).

2.8. IL-10 quantification. IL-10 was quantified from blood samples and culture medium with a specific ELISA (Bender MedSystems, Vienna, Austria and BD Biosciences, San Jose, California, USA). Blood samples of Apoe-KO and Apoe/Ccll-KO mice fed the HFD for 1 week or 2 months were collected in EDTA tubes to obtain plasma by centrifugation. For detection of IL-10 production in culture medium, splenocytes $\left(10^{6} / \mathrm{mL}\right)$ were stimulated with LPS (10 $\mu \mathrm{g} / \mathrm{ml})$ and IFN- $\gamma(100 \mathrm{UI} / \mathrm{ml})$ for 24 or 48 hours. For detection in culture medium of untreated BMdMs, supernatants were concentrated with Amicon Ultra-15 3,000 Nominal Molecular Weight Limit Centrifugal filters (Millipore, Burlington, Massachusetts, USA). The amount of IL-10 was normalized to total protein content.

2.9. Bone marrow transplantation and anti-CCR8 antibody treatment. CD45.1 Ldlr-KO recipient mice received $13 \mathrm{~Gy}$ of total body irradiation administered in two treatments from a 137Cs source (MARK 1-68 A; Shepherd and Associates). Bone marrow cells from CD45.2 Foxp3-mRFP mice were transplanted into $L d l r-K O$ recipients by i.v. injection immediately after irradiation. Approximately four weeks after transplantation, the chimeric condition of the mice was assessed by flow cytometry analysis of blood cells stained with a combination of FITCconjugated anti-CD45.1 and v450-conjugated anti-CD45.2 antibodies (both from Tonbo Bioscience, San Diego, California, USA), which confirmed that more than $90 \%$ of the cells analyzed were derived from the transplanted bone marrow cells.

One month after transplant, irradiated $L d l r-K O$ mice were challenged with HFD and received i.p. injections of either anti-CCR8 antibody or isotype control every two days for 1 week (100 $\mu \mathrm{g} / \mathrm{mouse})$. Atherosclerosis burden was quantified in the aortic root by hematoxylin/eosin staining. Treg content in the abdominal aorta was estimated by qPCR quantification of mRFP mRNA levels. Total RNA was isolated with Qiazol Lysis Reagent (Qiagen, Hilden, Germany) and isopropanol precipitation or with the RNeasy Mini kit (Qiagen). RNA concentration and purity were assessed from the ratio of absorbances at 260 and $280 \mathrm{~nm}$. Complementary DNA was synthesized from total RNA ( 0.1 to $1 \mu \mathrm{g}$ per reaction) with the High Capacity cDNA Reverse Transcription Kit (Applied Biosystems, Foster City, California, USA) using random primers and RNase Inhibitor. Quantitative PCR was performed with the ABI 
PRISM 7900HT Sequence Detection System using PCR Power SYBR Green PCR Master Mix (both from Applied Biosystems), with technical triplicates for each sample. Gene expression was analyzed by the comparative $\mathrm{Ct}$ method using the qBasePLUS software (Biogazelle, Zwijnaarde, Belgium) and the housekeeping gene $\beta$-actin as the internal control.

\subsection{Flow cytometry quantification of aortic and splenic immune cell content.}

Splenic immune cell content determination was performed as previously described [7, 41, 42]. Briefly, spleens from 11-month-old mice fed control diet were isolated and cellular content was obtained after mechanical processing. Cellular suspension was cultured in RPMI $+10 \% \mathrm{FCS}$ and stimulated with phorbol 12 myristate 13 acetate (PMA, $10 \mathrm{ng} / \mathrm{mL}$, Sigma-Aldrich) and ionomycin $(1 \mu \mathrm{M}$, Sigma-Aldrich) in the presence of brefeldin A $(5 \mu \mathrm{g} / \mathrm{mL}$, Sigma-Aldrich) for $4 \mathrm{~h}$ at $37{ }^{\circ} \mathrm{C}$. After washing, cells were fixed using Fixation/Permeabilization buffer (Invitrogen) for Th1 and Th2 determination and Foxp3 Fixation/Permeabilization buffer (BDPharmingen) for Treg staining. Aortic immune cell content quantification was performed as previously described [43, 44]. Aortas from 11-month-old Apoe-KO and Apoe/Ccll-DKO mice fed the HFD for 1 week were isolated and digested for $1 \mathrm{~h}$ at $37^{\circ} \mathrm{C}$ with an enzyme cocktail containing collagenase I (450 units/mL), collagenase XI (250 units $/ \mathrm{mL})$, DNase I (120 units $/ \mathrm{mL}$ ), and hyaluronidase (120 units/mL). After washing, cells were incubated with RPMI $+10 \% \mathrm{FCS}$ for $1 \mathrm{~h}$ at $37^{\circ} \mathrm{C}$ to restore internalized surface antigens. Splenic or aortic isolated cells were then stained as indicated with rat anti-mouse CD4 (clone RM4-5), rat anti-mouse CD25 (clone PC61.5), rat anti-mouse FOXP3 (clone FJK-16s), rat anti-mouse IFN $\gamma$ (clone XMG1.2), and rat anti-mouse IL-4 (clone 11B11) (all from Invitrogen) and were analyzed with a FACSCanto II flow cytometer (Becton Dickinson, Franklin Lakes, New Jersey, USA). Data were analyzed with FlowJo Software 10.1 (Flowjo LLC, Ashland, Oregon, USA).

2.11. Statistical analysis. Results are represented as mean \pm standard error of the mean (SEM). Statistical analyses were performed with Prism GraphPad Software (La Jolla, California, USA) and IBM SPSS (Armonk, New York, USA). Statistical significance was calculated by twotailed Student's t-test or ANOVA with Bonferroni's post-hoc multiple comparison test, as appropriate. Data normality was examined using Shapiro-Wilk test, whereas homoscedasticity was confirmed by Levene's test. Non-parametric tests were applied when necessary. Results were considered statistically significant for $\mathrm{p}$-values $<0.05$.

\section{Results}

3.1. CCL1 ablation aggravates atherosclerosis in fat-fed Apoe-KO mice. We first performed qPCR studies to quantify aortic Ccll mRNA expression in Apoe-KO mice fed either normal chow or a HFD for 1 week and 2 months, revealing a progressive induction of $C c l 1$ in fat-fed mice (Fig. 1A). To investigate which cell types contribute to Ccll upregulation under proinflammatory conditions in the artery wall, we performed experiments with primary cultures of VSMCs and BMdMs derived from Apoe-KO mice. Treatment of VSMCs with the 
proatherogenic agents $\mathrm{TNF} \alpha$ and IFN $\gamma$, but not with Ang II, upregulated Ccll mRNA expression level, with no significant effects on $C c r 8$ mRNA levels (Fig. 1B, left). Compared with VSMCs, BMdMs exhibited lower level of $C c l l$ and $C c r 8$ expression, which was not significantly affected by TNF $\alpha$, IFN $\gamma$, and AngII (Fig. 1B, right). These results suggest that VSMCs contribute significantly to $C c l l$ induction in the inflamed vessel wall of fat-fed ApoeKO mice.

To assess whether CCL1 plays a role in atherosclerosis, we generated Apoe/Ccll-DKO mice doubly deficient for Apoe and Ccll. As expected, body weight in mice fed normal chow increased significantly during post-natal development and was higher in males than in agematched females (Supplementary Fig. S1A). No between-genotype differences were seen in body weight except in the youngest male Apoe/Ccll-DKO mice, which were slightly leaner than age-matched Apoe-KO controls (Supplementary Fig. S1A). Likewise, Ccll deficiency did not affect plasma levels of total cholesterol, HDL-cholesterol, or triglycerides in mice fed either normal chow or challenged for 2 months with the HFD (Supplementary Fig. S1B). Fat feeding significantly increased total cholesterol and triglycerides while decreasing HDLcholesterol in plasma of mice of both genotypes.

We also analyzed circulating leukocyte populations. Consistent with previous studies [45], challenging mice for 2 months with HFD significantly increased the percentage of granulocytes and reduced the percentage of B-cells, without significantly affecting the relative abundance of monocytes and T-cells (Supplementary Fig. S1C). Ccll disruption did not affect the relative abundance of these circulating blood cells in either normal-diet-fed mice or HFDfed mice (Supplementary Fig. S1C). Similarly, CD4 T-cell percentages among CD45+ cells were undistinguishable in aorta, spleen and blood of Apoe-KO and Apoe/Ccll-DKO mice fed control diet, as revealed by flow cytometry (Supplementary Fig. S1D).

To assess the role of CCL1 in atherosclerosis, we quantified disease burden in aortic cross-sections of mice of both genotypes challenged with the HFD for 2 months. These studies revealed a significant increase in atheroma size in both the aortic root and ascending aorta of fat-fed Apoe/Ccll-DKO mice compared with Apoe-KO counterparts (Fig. 2A). We also assessed the consequence of inactivating Ccll on plaque composition. Apoe/Ccll-DKO atheromas had lower percentage of area covered by macrophages, and this difference reached statistical significance in the aortic root (Fig. 2B). However, no between-genotype differences were found in absolute macrophage content $\left(\mathrm{mm}^{2}\right.$ of Mac3-immunoreactive plaque area, Supplementary Table S1). Moreover, other neointimal parameters measured in aortic root and ascending aorta of fat-fed Apoe/Ccll-DKO mice did not show statistically-significant differences, neither when measured as percentages nor as absolute values, including necrotic core content and expression of CCR8, CD4 (T-cells), SM $\alpha$-actin (VSMCs), collagen, Ki67 (cell proliferation marker), and caspase 3 (apoptosis marker) (Fig. 3, and Supplementary Table S1). Supplementary Fig. S2 shows representative images of all markers analyzed in aortic root cross-sections of Apoe-KO and Apoe/Ccll-DKO mice.

3.2. CCL1 enhances leukocyte adhesion in vitro and in vivo. We next performed flow chamber experiments to investigate whether immobilized CCL1 can arrest peripheral leukocytes. Blood freshly collected from wild-type mice fed the control diet was perfused over CCL1-coated cover 
slips under flow conditions. Leukocyte adhesion was significantly higher in CCL1-coated coverslips than in vehicle-treated coverslips (Fig. 4A).

To investigate the role of CCL1 in in vivo leukocyte trafficking under pro-atherogenic conditions, we performed intravital microscopy in cremasteric arterioles of wild-type, Apoe$K O$, and Apoe/Ccll-DKO mice fed the HFD for 1 week. Leukocyte adhesion in arterioles was significantly higher in Apoe-KO mice than in wild-type controls and was abolished in Apoe/Ccl1-DKO mice (Fig. 4B). No between-genotype differences were observed in other hemodynamic parameters, such as arteriolar shear rate and diameter (Fig. 4B). Since Ccll disruption did not affect the percentage of circulating leukocyte populations (Supplementary Fig. S1C), our results suggest that the effects of CCL1 deficiency on leukocyte adhesion were due to CCL1-mediated leukocyte-vessel wall interactions.

\subsection{CCL1 regulates Treg accumulation and function, Th1/Th2 balance, and IL-10} production. CCL1 might regulate atherosclerosis development by affecting the recruitment, proliferation, and/or effector function of Th cells in atherosclerotic plaques. The observation that the percentage of CD4+ T-cells is unaltered in Apoe/Ccll-DKO aorta, spleen, and blood (Supplementary Fig. S1D) suggested that CCL1 does not affect the recruitment or proliferation of this cell type. However, CCL1 disruption was accompanied by a lower percentage of Tregs in aorta and spleen, with no effect in blood (Fig. 5A and Supplementary Fig. S3A). To assess whether CCL1 controls Treg function, we evaluated the ability of splenic Tregs (CD4+CD25+ T-cells) to inhibit the proliferation of naïve $\mathrm{CD} 4{ }^{+} \mathrm{CD} 25^{-} \mathrm{T}$-cells that were activated with anti-CD3 plus anti-CD28 antibodies. CCL1 disruption did not affect the proliferative activity of CD4+ T-cells isolated from spleen and lymph nodes (Fig. 5B). However, CCL1 disruption reduced Treg suppressive activity on T effector cells (Fig. 5C). Since IL-10 has been shown to mediate Treg inhibitory functions [46], we analyzed the production of IL-10 by quantifying its concentration in the culture medium of LPS+IFN $\gamma$ stimulated splenocytes. These in vitro studies showed reduced IL-10 production in splenocytes of fat-fed Apoe/Ccll-DKO mice (Fig. 5D). Likewise, Ccll disruption was associated with reduced IL-10 production by BMdMs (Fig. 5E), and plasma IL-10 levels were significantly lower in HFD-fed Apoe/Ccll-DKO mice than in Apoe-KO controls (Fig. 5F). Consistent with lower percentage of Tregs in aorta and spleen and IL-10 levels upon Ccll disruption, Apoe/Ccl1-DKO mice had a higher splenic Th1 content and a lower Th2 content than Apoe-KO controls (Fig. 5G and Supplementary Fig. S3B).

\subsection{Antibody-mediated CCR8 blockade inhibits aortic Treg recruitment and promotes} atherosclerosis. By interacting with its ligand CCL1, the receptor CCR8 plays a pivotal role in restraining immunity via Treg cell activation [31]. To further investigate the role of CCR8 in Treg function in the setting of atherosclerosis, we performed bone marrow transplant experiments in CD45.1 Ldlr-KO mice that were lethally-irradiated and reconstituted with bone marrow cells of Foxp3-mRFP knock-in mice, which express RFP in Tregs [35]. After recovery, transplanted mice were injected with CCR8 blocking antibody (or isotype control) and challenged with the HFD for 1 week. $R f p$ mRNA was then quantified by RT-PCR as a measure of aortic Treg infiltration. Compared with mice treated with isotype control antibody, animals injected with anti-CCR8 antibody had a lower content of RFP-expressing cells in the aorta (Fig. 
6A), suggesting a role for CCR8 in the recruitment of Tregs to the inflamed vessel wall. Inhibition of Treg recruitment upon treatment with anti-CCR8 in transplanted Ldlr-KO mice was accompanied by an increased atherosclerosis burden in the aortic root (Fig. 6B).

\section{Discussion}

Chemokines and their receptors play key roles at all stages of atherosclerosis by regulating multiple processes involved in disease initiation, progression, and complications (eg, leukocyte and platelet recruitment and activation, mobilization of immune cells from bone marrow and recruitment into atherosclerotic plaques, and cell differentiation, proliferation, apoptosis, and survival) [18-20]. The chemokine CCL1 and its receptor CCR8 regulate leukocyte trafficking in several pathophysiological scenarios [30, 47-50]. In the context of cardiovascular disease, previous studies showed CCL1 expression by endothelial cells in human arterial specimens and in injured mouse femoral arteries [28, 33, 51]. However, a direct role of the CCL1-CCR8 axis in atherosclerosis has not been demonstrated before. In this study, we establish for the first time a causal relationship between CCL1 expression and atherosclerosis development. We observed a progressive upregulation of CCL1 in the aorta of fat-fed Apoe-KO mice. Our studies with cultured cells stimulated with pro-inflammatory agents suggest that VSMCs, but not macrophages, contribute to CCL1 upregulation in the inflamed vessel wall. We also found that Ccll disruption aggravates HFD-induced atherosclerosis in the aortic root and ascending aorta of Apoe-KO mice without affecting body weight, plasma lipid levels, or the abundance of circulating leukocytes. Likewise, Ccll disruption did not affect important features of atherosclerotic plaques, such as the percentage of area occupied by T-cells, VSMCs, collagen, and necrotic cores, as well as the percentage of proliferating and apoptotic cells.

Immobilized CCL1 promoted leukocyte adhesion in in vitro flow chamber assays, and CCL1 ablation was associated with reduced leukocyte adherence in the in vivo intravital microscopy studies. Although fat-fed Apoe/Ccll-DKO mice had lower percentage of macrophages in atherosclerotic lesions in the aortic root (measured as percentage of Mac3immunoreactive area), total content of neointimal macrophages (measured as Mac3immunreactive area in atheromata) was similar to that seen in Apoe-KO controls. Moreover, Ccll disruption did not affect the relative and total macrophage content in atherosclerotic lesions in the ascending aorta. These findings suggest that macrophages do not contribute significantly to aggravated atherosclerosis upon Ccll disruption. We therefore turned our attention to Tregs, which express CCR8 [52, 53], and protect against atherosclerosis $[12,13$, 32]. Clinical studies also support a role for Tregs in human atherosclerosis [54-57]. Treg cells, but not effector $\mathrm{T}$ cells, decline during atherosclerotic lesion development [58], possibly as a result of phenotypic plasticity and differences between Treg and effector $\mathrm{T}$ cells in migration into lesions, susceptibility to death, and proliferative activity [5, 59]. Previous studies also showed the importance of CCL1 for Treg migration [60, 61]. We therefore hypothesized that CCL1 might affect Treg recruitment and/or function in atheromas. Our results show reduced 
Treg content in the spleen and aorta of Apoe/Ccll-DKO mice, without changes in blood, suggesting a role for CCL1 in Treg recruitment.

Tregs play critical roles in the inhibition of inflammatory responses and the regulation of autoimmunity [62, 63]. In line with previous studies implicating the CCL1-CCR8 axis in Treg function [31], our in vitro studies reveal that Apoe/Ccll-DKO Tregs have a reduced ability to inhibit T-effector cells, without affecting their proliferative activity. Tregs reduces $\mathrm{T}$ effector functions through a variety of mechanisms, including direct contact with antigen-presenting cells, destruction of inflammatory cells, and production of immunosuppressive regulators such as IL-10 [64-66]. CCL1 potentiates human Treg function in part through inducing IL-10 expression [31], and IL-10 deficiency increases the number and activity of inflammatory cells, promoting pro-inflammatory cytokine production and accelerating atherosclerosis in mice [14]. In our analysis, $C c l 1$ disruption impaired IL-10 production by BMdMs and LPS- and IFN $\gamma$ stimulated splenocytes obtained from mice fed the HFD for 2 months and markedly reduced plasma IL-10 in Apoe/Ccll-DKO mice fed the HFD for 1 week or 2 months compared with Apoe-KO controls. These findings suggest that reduced IL-10 production contributes to increased atherosclerosis induced by $\mathrm{Ccll}$ disruption. Further studies are required to assess whether $C c l l$ ablation affects the expression of other Treg-associated cytokines (eg., IL-35, TGF $\beta)$.

CCR8 is expressed predominantly in Tregs and also in small fractions of Th2 cells, monocytes, and NK cells, but not in Th1 cells [52, 67-71]. Human CCR8 has four known ligands: CCL1, CCL8, CCL16, and CCL18 [72-74]. Of these, CCL1 is unique in potentiating the suppressive function of human Tregs [31]. CCL1, CCL8, and CCL16 have also been identified as mouse CCR8 ligands, with CCL1 being considered the only booster of the suppressive activities of mouse Tregs [31]. Our results show that treatment of fat-fed Ldlr-KO mice with CCR8-blocking antibodies reduces Treg content in aorta and enhances aortic atherosclerosis, consistent with a role for this receptor in Treg recruitment. Previous studies in Tregs have shown that CCL1 binding to CCR8 upregulates STAT3-dependent Foxp3 expression while inducing CD39, Granzyme B, and IL-10 [31]. Further studies are warranted to assess whether modulation of these factors in Tregs contributes to the regulation of atherosclerosis by the CCL1-CCR8 axis.

\section{Conclusions}

Our findings demonstrate increased atherosclerosis upon inactivation of the CCL1-CCR8 axis, which is mediated by reduced Treg recruitment into the inflamed artery wall and defective Treg function, possibly due to increases in both IL-10 production and Th1:Th2 ratio. Further studies are warranted to assess whether treatment with CCL1 offers a possible route to atherosclerosis inhibition. 


\section{Acknowledgments}

We thank J. Mateos for technical assistance, S. Bartlett for English editing, G. Marquez for providing Ccll-KO mice, RA. Flavell for providing Foxp3-mRFP mice, and the CNIC and IBVCSIC Animal Facilities for animal care. This study was supported by the Spanish Ministerio de Ciencia, Innovación y Universidades (MCIU, grants SAF2016-79490-R and SAF2014-57845R) and the Instituto de Salud Carlos III (ISCIII, grants PI14/00526, PI17/01395, CP11/00145, and CPII16/00022) with co-funding from the European Regional Development Fund (ERDF, "Una manera de hacer Europa"), the Fundación Ramón Areces, European Union (EuroCellNet COST Action CA15214) and the INSERM. VZG is supported by the ISCIII, JMG-G by the ISCIII Miguel Servet Program and the Instituto de Investigación Sanitaria Hospital 12 de Octubre (imas12), AdMM by the MCIU (predoctoral contract BES-2014-06779), and ZM by a British Heart Foundation Professorship. The CNIC is supported by the MCIU and the Pro CNIC Foundation and is a Severo Ochoa Center of Excellence (SEV-2015-0505).

\section{Author contributions}

MVC and JMGG, designed and performed experiments, analyzed data, and prepared figures and the manuscript. VZ, YNAN, CSR, PMS, AdMM, HAO and MJAM, performed experiments and analyzed data. MJS, CW, LK and ZM, provided advice on the design and analysis of experiments and critically read and edited the manuscript. JG critically read and edited the manuscript. VA supervised the research, project planning, and data interpretation and prepared the manuscript. All authors read and approved the manuscript.

\section{Conflicts of interest}

The authors report no commercial or proprietary interest in any product or concept discussed in this article. 


\section{References}

[1] Savji N, Rockman CB, Skolnick AH, Guo Y, Adelman MA, Riles T et al. Association between advanced age and vascular disease in different arterial territories: a population database of over 3.6 million subjects. J Am Coll Cardiol 2013; 61:1736-43.

[2] D'Agostino RB, Sr., Vasan RS, Pencina MJ, Wolf PA, Cobain M, Massaro JM et al. General cardiovascular risk profile for use in primary care: the Framingham Heart Study. Circulation 2008; 117:743-53.

[3] Ross R. Atherosclerosis--an inflammatory disease. N Engl J Med 1999; 340:115-26.

[4] Galkina E, Ley K. Immune and inflammatory mechanisms of atherosclerosis (*). Annu Rev Immunol 2009; 27:165-97.

[5] Tabas I, Lichtman AH. Monocyte-Macrophages and T Cells in Atherosclerosis. Immunity 2017; 47:621-34.

[6] Emeson EE, Shen ML, Bell CG, Qureshi A. Inhibition of atherosclerosis in CD4 T-cellablated and nude (nu/nu) C57BL/6 hyperlipidemic mice. Am J Pathol 1996; 149:675-85.

[7] Iborra S, Gonzalez-Granado JM. In Vitro Differentiation of Naive CD4(+) T Cells: A Tool for Understanding the Development of Atherosclerosis. Methods Mol Biol 2015; 1339:177-89.

[8] Elhage R, Jawien J, Rudling M, Ljunggren HG, Takeda K, Akira S et al. Reduced atherosclerosis in interleukin-18 deficient apolipoprotein E-knockout mice. Cardiovasc Res 2003; 59:234-40.

[9] Gupta S, Pablo AM, Jiang X, Wang N, Tall AR, Schindler C. IFN-gamma potentiates atherosclerosis in ApoE knock-out mice. J Clin Invest 1997; 99:2752-61.

[10] Buono C, Come CE, Stavrakis G, Maguire GF, Connelly PW, Lichtman AH. Influence of interferon-gamma on the extent and phenotype of diet-induced atherosclerosis in the LDLR-deficient mouse. Arterioscler Thromb Vasc Biol 2003; 23:454-60.

[11] Buono C, Binder CJ, Stavrakis G, Witztum JL, Glimcher LH, Lichtman AH. T-bet deficiency reduces atherosclerosis and alters plaque antigen-specific immune responses. Proc Natl Acad Sci U S A 2005; 102:1596-601.

[12] Ait-Oufella H, Salomon BL, Potteaux S, Robertson AK, Gourdy P, Zoll J et al. Natural regulatory $\mathrm{T}$ cells control the development of atherosclerosis in mice. Nat Med 2006; 12:178-80.

[13] Klingenberg R, Gerdes N, Badeau RM, Gistera A, Strodthoff D, Ketelhuth DF et al. Depletion of FOXP3+ regulatory $\mathrm{T}$ cells promotes hypercholesterolemia and atherosclerosis. J Clin Invest 2013; 123:1323-34.

[14] Mallat Z, Besnard S, Duriez M, Deleuze V, Emmanuel F, Bureau MF et al. Protective role of interleukin-10 in atherosclerosis. Circ Res 1999; 85:e17-24.

[15] Pinderski Oslund LJ, Hedrick CC, Olvera T, Hagenbaugh A, Territo M, Berliner JA et al. Interleukin-10 blocks atherosclerotic events in vitro and in vivo. Arterioscler Thromb Vasc Biol 1999; 19:2847-53.

[16] Mallat Z, Gojova A, Marchiol-Fournigault C, Esposito B, Kamate C, Merval R et al. Inhibition of transforming growth factor-beta signaling accelerates atherosclerosis and induces an unstable plaque phenotype in mice. Circ Res 2001; 89:930-4. 
[17] Robertson AK, Rudling M, Zhou X, Gorelik L, Flavell RA, Hansson GK. Disruption of TGF-beta signaling in T cells accelerates atherosclerosis. J Clin Invest 2003; 112:134250.

[18] Libby P, Hansson GK. Inflammation and immunity in diseases of the arterial tree: players and layers. Circ Res 2015; 116:307-11.

[19] Ramji DP, Davies TS. Cytokines in atherosclerosis: Key players in all stages of disease and promising therapeutic targets. Cytokine Growth Factor Rev 2015; 26:673-85.

[20] Zernecke A, Shagdarsuren E, Weber C. Chemokines in atherosclerosis: an update. Arterioscler Thromb Vasc Biol 2008; 28:1897-908.

[21] Miller MD, Hata S, De Waal Malefyt R, Krangel MS. A novel polypeptide secreted by activated human T lymphocytes. J Immunol 1989; 143:2907-16.

[22] Harpel PC, Haque NS. Chemokine receptor-8: potential role in atherogenesis. Isr Med Assoc J 2002; 4:1025-7.

[23] Charo IF, Ransohoff RM. The many roles of chemokines and chemokine receptors in inflammation. N Engl J Med 2006; 354:610-21.

[24] Cantor J, Haskins K. Recruitment and activation of macrophages by pathogenic CD4 T cells in type 1 diabetes: evidence for involvement of CCR8 and CCL1. J Immunol 2007; 179:5760-7.

[25] Montes-Vizuet R, Vega-Miranda A, Valencia-Maqueda E, Negrete-Garcia MC, Velasquez JR, Teran LM. CC chemokine ligand 1 is released into the airways of atopic asthmatics. Eur Respir J 2006; 28:59-67.

[26] Kim HO, Cho SI, Chung BY, Ahn HK, Park CW, Lee CH. Expression of CCL1 and CCL18 in atopic dermatitis and psoriasis. Clin Exp Dermatol 2012; 37:521-6.

[27] Gombert M, Dieu-Nosjean MC, Winterberg F, Bunemann E, Kubitza RC, Da Cunha L et al. CCL1-CCR8 interactions: an axis mediating the recruitment of $\mathrm{T}$ cells and Langerhans-type dendritic cells to sites of atopic skin inflammation. J Immunol 2005; 174:5082-91.

[28] Haque NS, Fallon JT, Pan JJ, Taubman MB, Harpel PC. Chemokine receptor-8 (CCR8) mediates human vascular smooth muscle cell chemotaxis and metalloproteinase-2 secretion. Blood 2004; 103:1296-304.

[29] Matsukawa A, Kudoh S, Sano G, Maeda T, Ito T, Lukacs NW et al. Absence of CC chemokine receptor 8 enhances innate immunity during septic peritonitis. FASEB $\mathrm{J}$ 2006; 20:302-4.

[30] Heymann F, Hammerich L, Storch D, Bartneck M, Huss S, Russeler V et al. Hepatic macrophage migration and differentiation critical for liver fibrosis is mediated by the chemokine receptor C-C motif chemokine receptor 8 in mice. Hepatology 2012; 55:898909.

[31] Barsheshet Y, Wildbaum G, Levy E, Vitenshtein A, Akinseye C, Griggs J et al. CCR8(+)FOXp3(+) Treg cells as master drivers of immune regulation. Proc Natl Acad Sci U S A 2017; 114:6086-91.

[32] Spitz C, Winkels H, Burger C, Weber C, Lutgens E, Hansson GK et al. Regulatory T cells in atherosclerosis: critical immune regulatory function and therapeutic potential. Cell Mol Life Sci 2016; 73:901-22. 
[33] Haque NS, Zhang X, French DL, Li J, Poon M, Fallon JT et al. CC chemokine I-309 is the principal monocyte chemoattractant induced by apolipoprotein(a) in human vascular endothelial cells. Circulation 2000; 102:786-92.

[34] Bernardini G, Spinetti G, Ribatti D, Camarda G, Morbidelli L, Ziche M et al. I-309 binds to and activates endothelial cell functions and acts as an angiogenic molecule in vivo. Blood 2000; 96:4039-45.

[35] Wan YY, Flavell RA. Identifying Foxp3-expressing suppressor T cells with a bicistronic reporter. Proc Natl Acad Sci U S A 2005; 102:5126-31.

[36] Mira E, Leon B, Barber DF, Jimenez-Baranda S, Goya I, Almonacid L et al. Statins induce regulatory $\mathrm{T}$ cell recruitment via a CCL1 dependent pathway. J Immunol 2008; 181:3524-34.

[37] Gonzalez-Navarro H, Vinue A, Vila-Caballer M, Fortuno A, Beloqui O, Zalba G et al. Molecular mechanisms of atherosclerosis in metabolic syndrome: role of reduced IRS2dependent signaling. Arterioscler Thromb Vasc Biol 2008; 28:2187-94.

[38] Gonzalez-Navarro H, Vila-Caballer M, Pastor MF, Vinue A, White MF, Burks D et al. Plasma insulin levels predict the development of atherosclerosis when IRS2 deficiency is combined with severe hypercholesterolemia in apolipoprotein E-null mice. Front Biosci 2007; 12:2291-8.

[39] Sunderkotter C, Nikolic T, Dillon MJ, Van Rooijen N, Stehling M, Drevets DA et al. Subpopulations of mouse blood monocytes differ in maturation stage and inflammatory response. J Immunol 2004; 172:4410-7.

[40] Company C, Piqueras L, Naim Abu Nabah Y, Escudero P, Blanes JI, Jose PJ et al. Contributions of ACE and mast cell chymase to endogenous angiotensin II generation and leucocyte recruitment in vivo. Cardiovasc Res 2011; 92:48-56.

[41] Toribio-Fernandez R, Zorita V, Rocha-Perugini V, Iborra S, Martinez Del Hoyo G, Chevre $\mathrm{R}$ et al. Lamin A/C augments Th1 differentiation and response against vaccinia virus and Leishmania major. Cell Death Dis 2018; 9:9.

[42] Toribio-Fernandez R, Zorita V, Herrero-Fernandez B, Gonzalez-Granado JM. An In Vivo Mouse Model to Measure Naive CD4 T Cell Activation, Proliferation and Th1 Differentiation Induced by Bone Marrow-derived Dendritic Cells. J Vis Exp 2018.

[43] Taleb S, Herbin O, Ait-Oufella H, Verreth W, Gourdy P, Barateau V et al. Defective leptin/leptin receptor signaling improves regulatory $\mathrm{T}$ cell immune response and protects mice from atherosclerosis. Arterioscler Thromb Vasc Biol 2007; 27:2691-8.

[44] Galkina E, Kadl A, Sanders J, Varughese D, Sarembock IJ, Ley K. Lymphocyte recruitment into the aortic wall before and during development of atherosclerosis is partially L-selectin dependent. J Exp Med 2006; 203:1273-82.

[45] Tie G, Messina KE, Yan J, Messina JA, Messina LM. Hypercholesterolemia induces oxidant stress that accelerates the ageing of hematopoietic stem cells. J Am Heart Assoc 2014; 3:e000241.

[46] Shevach EM, Thornton AM. tTregs, pTregs, and iTregs: similarities and differences. Immunol Rev 2014; 259:88-102.

[47] Mikhak Z, Fukui M, Farsidjani A, Medoff BD, Tager AM, Luster AD. Contribution of CCR4 and CCR8 to antigen-specific $\mathrm{T}(\mathrm{H}) 2$ cell trafficking in allergic pulmonary inflammation. J Allergy Clin Immunol 2009; 123:67-73 e3. 
[48] Das S, Sarrou E, Podgrabinska S, Cassella M, Mungamuri SK, Feirt N et al. Tumor cell entry into the lymph node is controlled by CCL1 chemokine expressed by lymph node lymphatic sinuses. J Exp Med 2013; 210:1509-28.

[49] Zen Y, Liberal R, Nakanuma Y, Heaton N, Portmann B. Possible involvement of CCL1CCR8 interaction in lymphocytic recruitment in IgG4-related sclerosing cholangitis. J Hepatol 2013; 59:1059-64.

[50] Coghill JM, Fowler KA, West ML, Fulton LM, van Deventer H, McKinnon KP et al. CC chemokine receptor 8 potentiates donor Treg survival and is critical for the prevention of murine graft-versus-host disease. Blood 2013; 122:825-36.

[51] Haque NS, Fallon JT, Taubman MB, Harpel PC. The chemokine receptor CCR8 mediates human endothelial cell chemotaxis induced by I-309 and Kaposi sarcoma herpesvirusencoded vMIP-I and by lipoprotein(a)-stimulated endothelial cell conditioned medium. Blood 2001; 97:39-45.

[52] Freeman CM, Chiu BC, Stolberg VR, Hu J, Zeibecoglou K, Lukacs NW et al. CCR8 is expressed by antigen-elicited, IL-10-producing CD4+CD25+ T cells, which regulate Th2-mediated granuloma formation in mice. J Immunol 2005; 174:1962-70.

[53] Sebastiani S, Allavena P, Albanesi C, Nasorri F, Bianchi G, Traidl C et al. Chemokine receptor expression and function in $\mathrm{CD} 4+\mathrm{T}$ lymphocytes with regulatory activity. $\mathrm{J}$ Immunol 2001; 166:996-1002.

[54] Zhang WC, Wang J, Shu YW, Tang TT, Zhu ZF, Xia N et al. Impaired thymic export and increased apoptosis account for regulatory $\mathrm{T}$ cell defects in patients with non-ST segment elevation acute coronary syndrome. J Biol Chem 2012; 287:34157-66.

[55] Wigren M, Bjorkbacka H, Andersson L, Ljungcrantz I, Fredrikson GN, Persson M et al. Low levels of circulating CD4+FoxP3+ $\mathrm{T}$ cells are associated with an increased risk for development of myocardial infarction but not for stroke. Arterioscler Thromb Vasc Biol 2012; 32:2000-4.

[56] Ammirati E, Cianflone D, Banfi M, Vecchio V, Palini A, De Metrio M et al. Circulating CD4+CD25hiCD127lo regulatory T-Cell levels do not reflect the extent or severity of carotid and coronary atherosclerosis. Arterioscler Thromb Vasc Biol 2010; 30:1832-41.

[57] Mor A, Luboshits G, Planer D, Keren G, George J. Altered status of CD4(+)CD25(+) regulatory T cells in patients with acute coronary syndromes. Eur Heart J 2006; 27:25307.

[58] Maganto-Garcia E, Tarrio ML, Grabie N, Bu DX, Lichtman AH. Dynamic changes in regulatory $\mathrm{T}$ cells are linked to levels of diet-induced hypercholesterolemia. Circulation 2011; 124:185-95.

[59] Heller EA, Liu E, Tager AM, Yuan Q, Lin AY, Ahluwalia N et al. Chemokine CXCL10 promotes atherogenesis by modulating the local balance of effector and regulatory $\mathrm{T}$ cells. Circulation 2006; 113:2301-12.

[60] Colantonio L, Iellem A, Sinigaglia F, D'Ambrosio D. Skin-homing CLA+ T cells and regulatory $\mathrm{CD} 25+\mathrm{T}$ cells represent major subsets of human peripheral blood memory $\mathrm{T}$ cells migrating in response to CCL1/I-309. Eur J Immunol 2002; 32:3506-14.

[61] Iellem A, Mariani M, Lang R, Recalde H, Panina-Bordignon P, Sinigaglia F et al. Unique chemotactic response profile and specific expression of chemokine receptors CCR4 and CCR8 by CD4(+)CD25(+) regulatory T cells. J Exp Med 2001; 194:847-53. 
[62] Wing K, Sakaguchi S. Regulatory T cells exert checks and balances on self tolerance and autoimmunity. Nat Immunol 2010; 11:7-13.

[63] Shevach EM. Mechanisms of foxp3+ T regulatory cell-mediated suppression. Immunity 2009; 30:636-45.

[64] Yamaguchi T, Wing JB, Sakaguchi S. Two modes of immune suppression by Foxp3(+) regulatory $\mathrm{T}$ cells under inflammatory or non-inflammatory conditions. Semin Immunol 2011; 23:424-30.

[65] Saraiva M, O'Garra A. The regulation of IL-10 production by immune cells. Nat Rev Immunol 2010; 10:170-81.

[66] Shevach EM, DiPaolo RA, Andersson J, Zhao DM, Stephens GL, Thornton AM. The lifestyle of naturally occurring CD4+ CD25+ Foxp3+ regulatory T cells. Immunol Rev 2006; 212:60-73.

[67] D'Ambrosio D, Iellem A, Bonecchi R, Mazzeo D, Sozzani S, Mantovani A et al. Selective up-regulation of chemokine receptors CCR4 and CCR8 upon activation of polarized human type 2 Th cells. J Immunol 1998; 161:5111-5.

[68] Zingoni A, Soto H, Hedrick JA, Stoppacciaro A, Storlazzi CT, Sinigaglia F et al. The chemokine receptor CCR 8 is preferentially expressed in Th2 but not Th1 cells. J Immunol $1998 ; 161: 547-51$.

[69] Inngjerdingen M, Damaj B, Maghazachi AA. Expression and regulation of chemokine receptors in human natural killer cells. Blood 2001; 97:367-75.

[70] Inngjerdingen M, Damaj B, Maghazachi AA. Human NK cells express CC chemokine receptors 4 and 8 and respond to thymus and activation-regulated chemokine, macrophage-derived chemokine, and I-309. J Immunol 2000; 164:4048-54.

[71] Roos RS, Loetscher M, Legler DF, Clark-Lewis I, Baggiolini M, Moser B. Identification of CCR8, the receptor for the human CC chemokine I-309. J Biol Chem 1997; 272:17251-4.

[72] Islam SA, Chang DS, Colvin RA, Byrne MH, McCully ML, Moser B et al. Mouse CCL8, a CCR8 agonist, promotes atopic dermatitis by recruiting IL-5+ T(H)2 cells. Nat Immunol 2011; 12:167-77.

[73] Howard OM, Dong HF, Shirakawa AK, Oppenheim JJ. LEC induces chemotaxis and adhesion by interacting with CCR1 and CCR8. Blood 2000; 96:840-5.

[74] Islam SA, Ling MF, Leung J, Shreffler WG, Luster AD. Identification of human CCR8 as a CCL18 receptor. J Exp Med 2013; 210:1889-98. 


\section{FIGURE LEGENDS}

Fig. 1. Induction of $C c l 1$ expression in aorta of fat-fed $A p o e-K O$ mice, and $C c l 1$ and $C c r 8$ expression analysis in primary VSMCs and BMdMs. (A) RT-qPCR analysis of $\mathrm{Ccll}$ expression in aorta of Apoe-KO mice fed a control diet or an atherogenic high-fat diet (HFD) for 1 week or 2 months. Results are expressed relative to Apoe-KO mice fed control diet. (B) RT-qPCR analysis of $\mathrm{Ccll}$ and $\mathrm{Ccr} 8$ expression in primary VSMCs and BMdMs derived from Apoe-KO mice. Cells were incubated during $20 \mathrm{~h}$ with the indicated doses of tumor necrosis factor $\alpha(\mathrm{TNF} \alpha)$, interferon $\gamma$ (IFN $\gamma)$ and angiotensin II (AngII). Results are expressed relative to basal expression in untreated VSMCs. ${ }^{*}, \mathrm{p}<0.05$ vs. basal condition. In A, $\mathrm{n}$ indicates the number of samples (each containing 2 aortas). In $\mathrm{B}, \mathrm{n}$ indicates the number of culture plates (each containing VSMCs or BMdM from 3 mice).

Fig. 2. Ccl1 disruption aggravates diet-induced atherosclerosis. (A) Quantification of atherosclerosis burden measured as intimal area in aortic root and ascending aorta crosssections of mice fed the HFD for 2 months. (B) Quantification of neointimal macrophage content in cross-sections of aortic root and ascending aorta of mice fed the high-fat diet for 2 months. Data are the \% of the neointimal area covered by immunohistochemistry-detected Mac3-immunoreactive macrophages. Total macrophage content quantified as $\mathrm{mm}^{2}$ of Mac3immunoreactive areas is shown in Supplementary Table S1. (C) Representative specimens immunostained for Mac3 and counterstained with hematoxylin. The red line marks the boundaries of atherosclerotic lesions. Scale bar: $500 \mu \mathrm{m} . n=$ number of mice. ${ }^{*}, p<0.05$.

Fig. 3. Ccl1 disruption does not affect aortic CCR8 expression or atherosclerotic plaque characteristics. Quantified immunohistopathological analysis of aortic root and ascending aorta from 2-month-HFD-fed Apoe-KO and Apoe/CCL1-DKO mice. Cross-sections were analyzed for neointimal content of CCR8, CD4+ T-cells, necrotic core, VSMCs (SM $\alpha$-actin+), collagen (Masson's trichrome staining), proliferating cells (Ki67+), and apoptosis (caspase 3+). $\mathrm{n}=$ number of mice. Representative images are shown in Supplementary Fig. S2, and results expressed as total area are in Supplementary Table S1.

Fig. 4. Ccl1 mediates leukocyte adhesion in vitro and in vivo. (A) In vitro leukocyte adhesion in flow chamber assays. Whole blood of wild-type mice was perfused in flow chambers containing vehicle-coated or CCL1-coated coverslips. $n=$ number of coverslips. (B) In vivo intravital microscopy analysis of leukocyte adhesion, shear rate, and vessel diameter in cremaster arterioles of 1-week-HFD-fed wild-type, Apoe-KO, and Apoe/Ccl1-DKO mice. $\mathrm{n}=$ number of mice. ${ }^{* *}, \mathrm{p}<0.01 ; * * *, \mathrm{p}<0.001$ 
Fig. 5. Ccl1 disruption increases the Th1:Th2 ratio, inhibits Treg recruitment and suppressive function, and reduces CD4+ T cell IL-10 production and plasma IL-10 levels. (A) Flow cytometry-determined content of Tregs $\left(\mathrm{CD}^{+} \mathrm{CD}_{2} 5^{\text {high }} \mathrm{FOXP}^{+}\right)$as a percentage of $\mathrm{CD}^{+} \mathrm{T}$-cells in aorta, spleen, and blood of 11-month-old control-diet-fed mice. Results are shown relative to Apoe-KO mice for aorta and as bare percentages for spleen and blood $(\mathrm{n}=7$ Apoe-KO; $\mathrm{n}=8$ Apoe/Ccll-DKO). (B) Proliferation of $\mathrm{CD}^{+} \mathrm{T}$ cells isolated from spleen and lymph nodes of 11-month-old control-diet-fed Apoe-KO and Apoe/Ccll-DKO mice (triplicates of 3 pooled mice per genotype). (C) Inhibition of wild-type effector $\mathrm{T}$ cell proliferation upon co-culture with splenic $\mathrm{CD} 4{ }^{+} \mathrm{CD} 25^{+}$Tregs isolated from 11-month-old control-diet-fed Apoe$K O$ and Apoe/Ccll-DKO mice (triplicates of 3 pooled mice per genotype). The effector $\mathrm{T}$ cell:Treg ratio is shown in the horizontal axis. (D) IL-10 production in LPS- and IFN $\gamma$ stimulated splenocytes of mice fed the HFD for 2 months ( $n=9$ mice per genotype). (E) IL-10 production in BMdMs of Apoe-KO mice fed the HFD for 2 months ( $\mathrm{n}=4$ culture plates, each containing BMdMs from 3 mice per genotype). (F) Plasma IL-10 in fat-fed mice ( $\mathrm{n}=7$ Apoe$K O$ mice and $\mathrm{n}=5$ Apoe/Ccll-DKO mice fed the HFD for 1 week; $\mathrm{n}=8 \mathrm{Apoe}-\mathrm{KO}$ and Apoe/Ccll$D K O$ mice fed the HFD for 2 months). (G) Flow cytometry-determined percentage of Th1 $\left(\mathrm{CD} 4^{+} \mathrm{IFN} \gamma^{+}\right.$and $\left.\mathrm{CD} 4^{+} \mathrm{IL}-2^{+}\right)$and $\mathrm{Th} 2\left(\mathrm{CD} 4^{+} \mathrm{IL}-4^{+}\right)$leukocytes in spleen of 11 -month-old control-diet-fed mice. Results are expressed relative to total $\mathrm{CD} 4^{+}$leukocytes $(\mathrm{n}=3$ mice per genotype). *, $\mathrm{p}<0.05 ; * *, \mathrm{p}<0.01$.

Fig. 6. Antibody-mediated CCR8 blockade inhibits aortic Treg recruitment and promotes atherosclerosis development. $L d l r$ - $K O$ mice were gamma-irradiated and transplanted with bone marrow cells of Foxp3/mRFP mice (expressing RFP in Tregs). One month after irradiation and transplant, mice were challenged with the HFD and injected with either anti-CCR8 antibody or isotype control antibody every 2 days. Mice were sacrificed after 1 week. (A) Relative Treg accumulation in aorta quantified from qPCR-determined RFP expression. (B) Atherosclerosis burden determined as the intimal area in the aortic root of $L d l r-K O$ mice fed the HFD for 1 week. Representative hematoxylin/eosin-stained cross-sections are shown, with red line marking atherosclerotic lesion boundaries. $n=$ number of mice. ${ }^{*}, p<0.05$. 
A

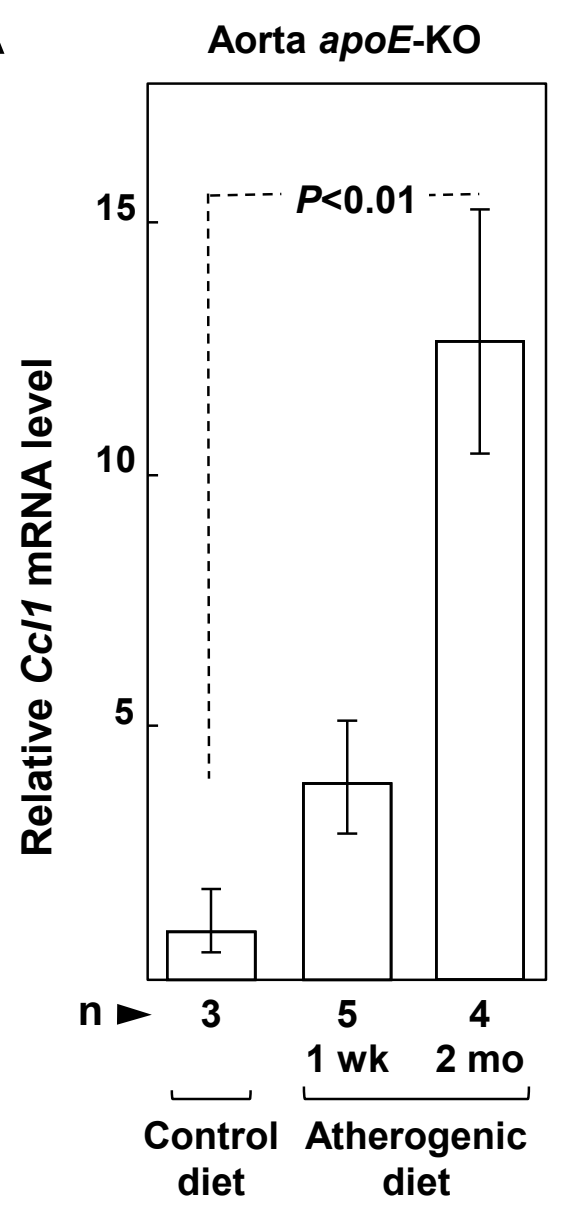

B
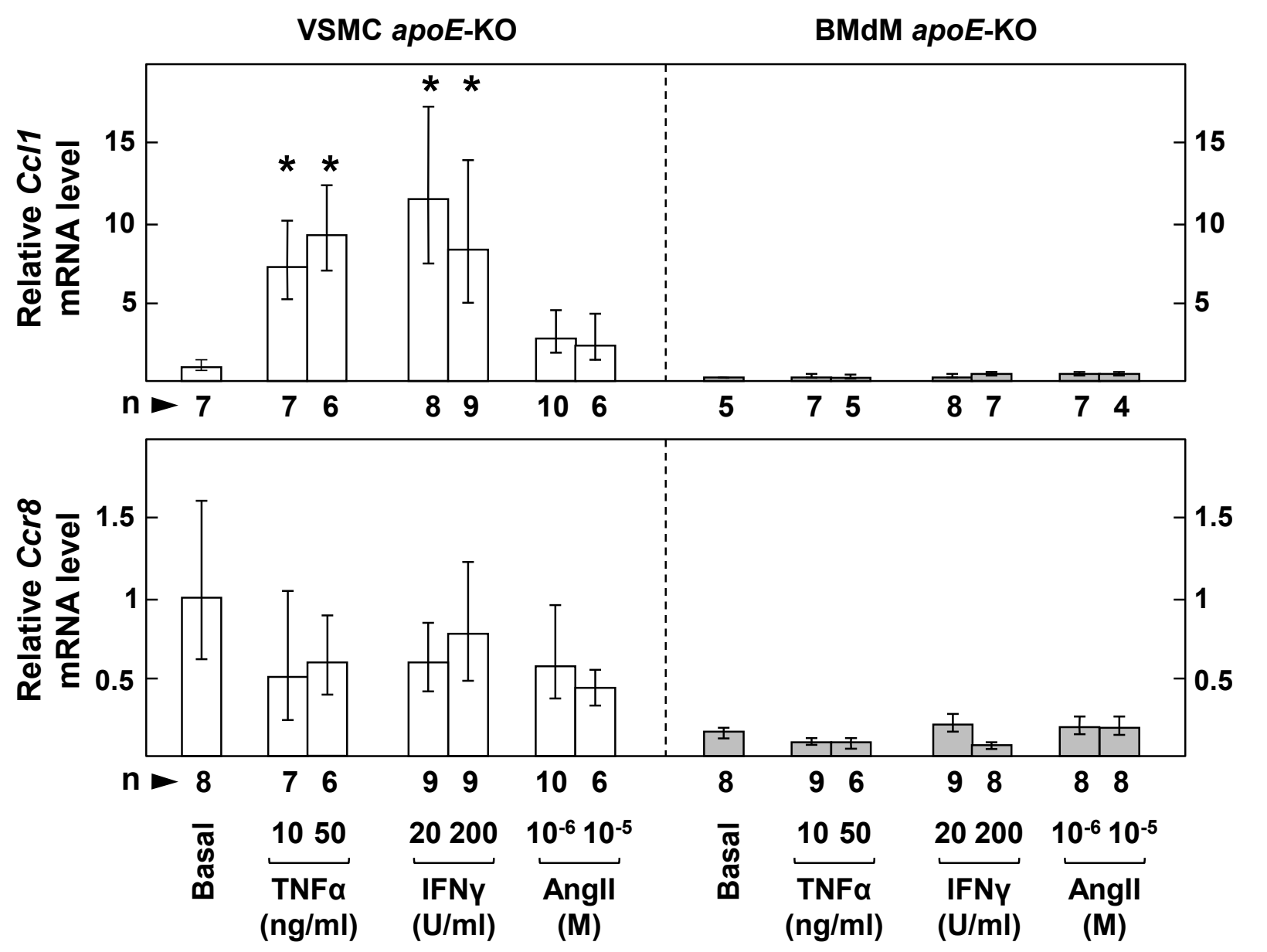
A
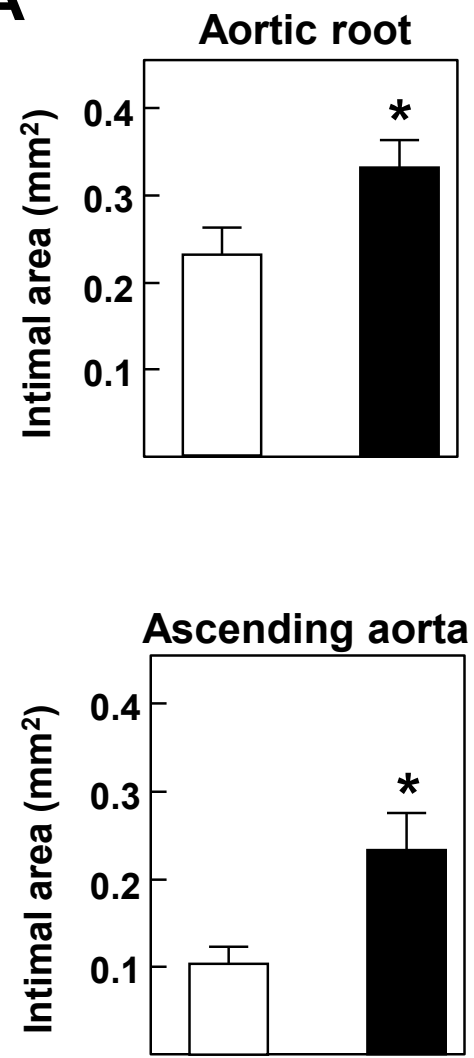

Apoe-KO (n=10)
B

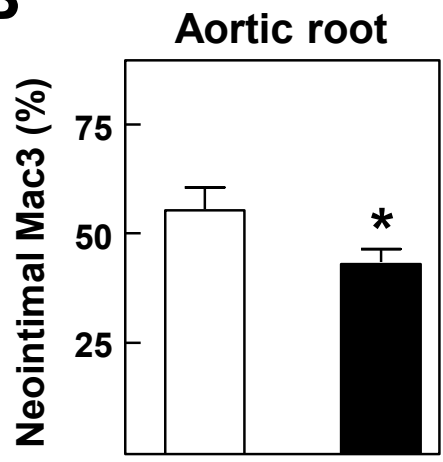

Ascending aorta

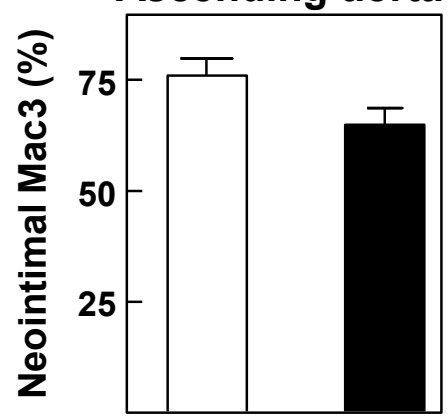

Apoe/Ccl1-DKO
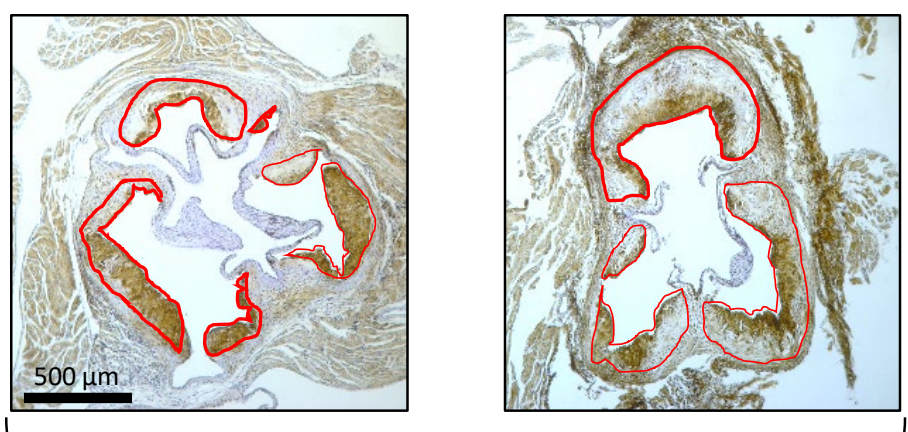

Aortic root

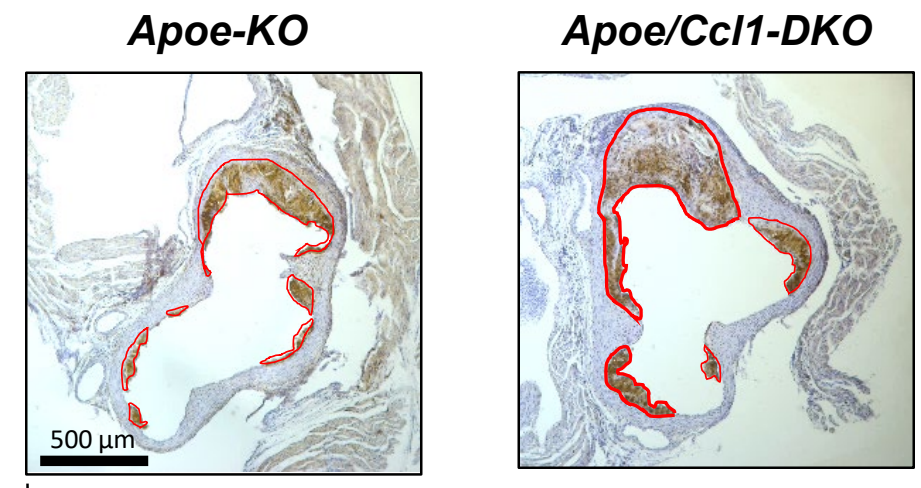

Ascending aorta

Apoe/Cc/1-DKO (n=14) 

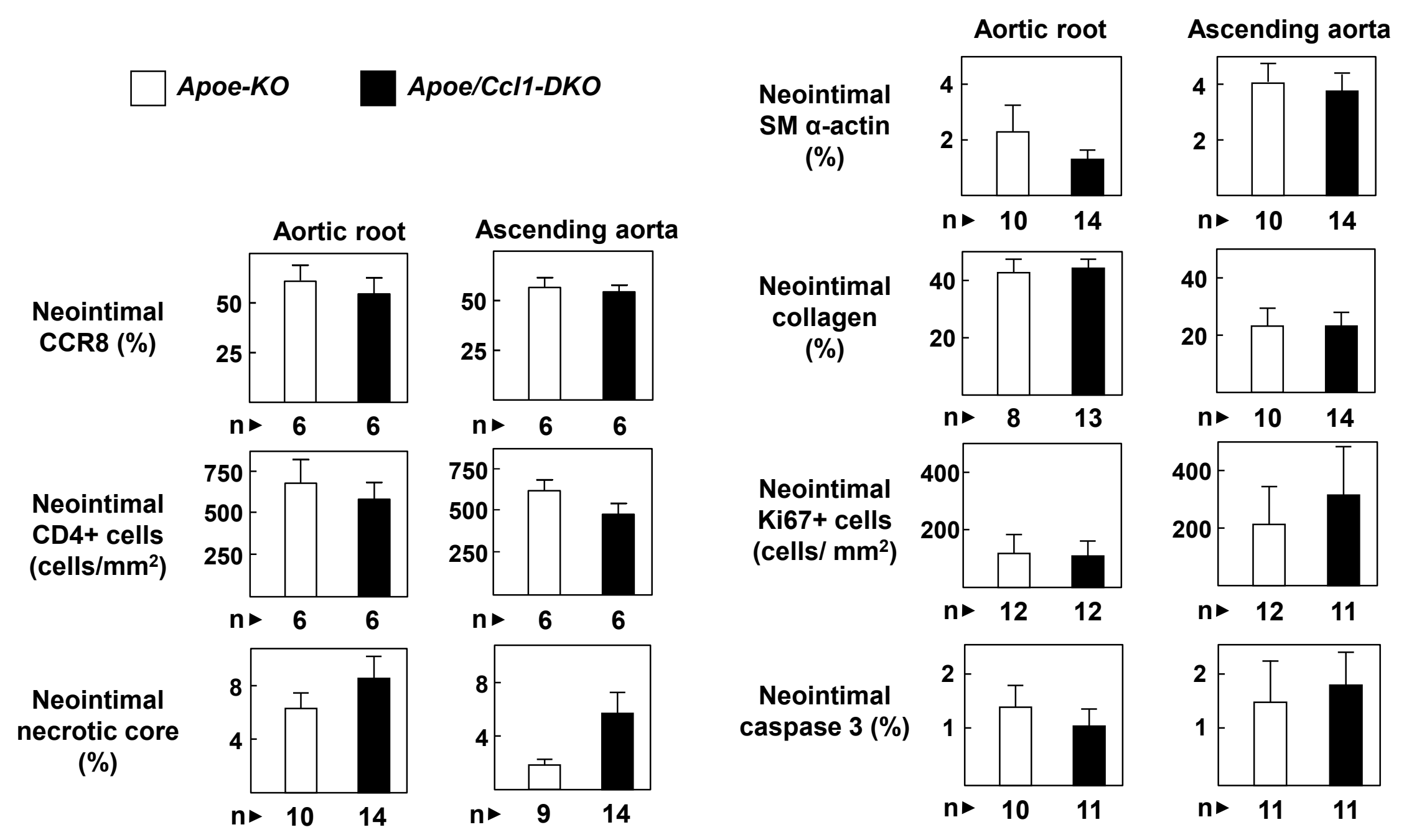
A

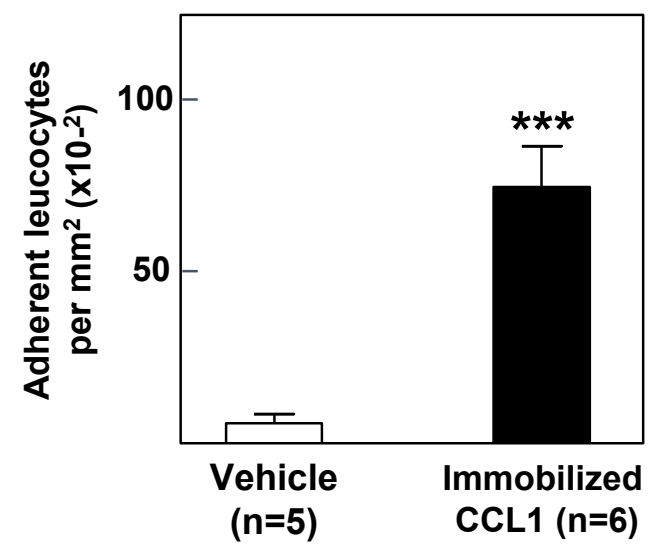

B

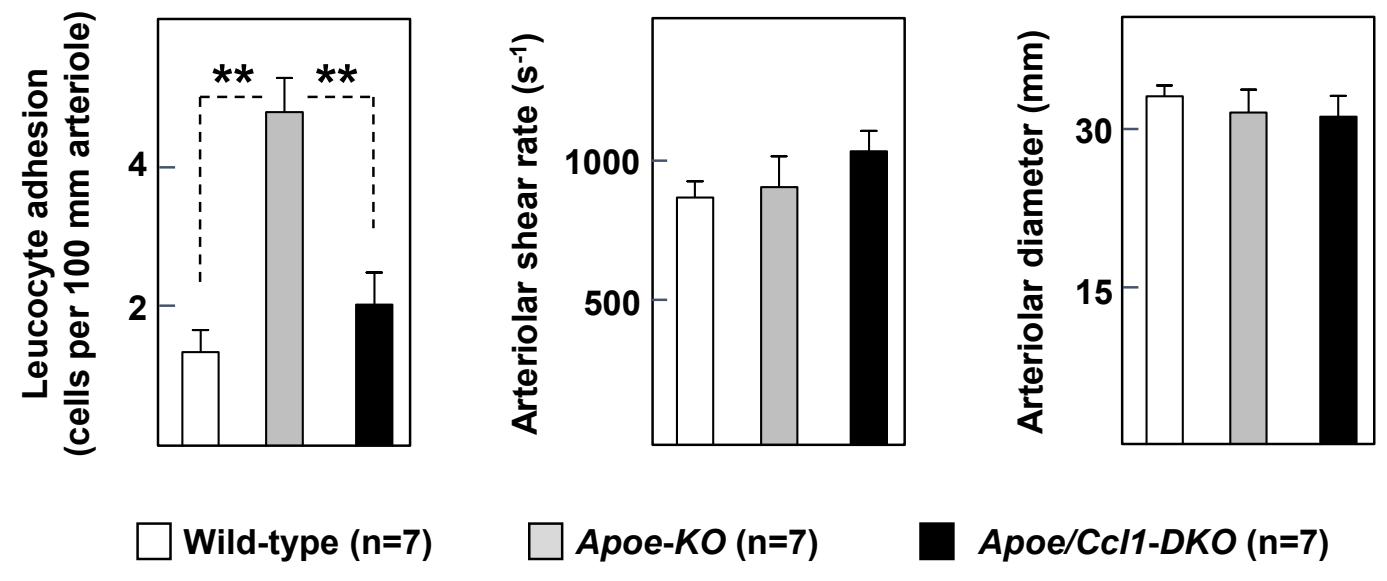

1 week HFD 


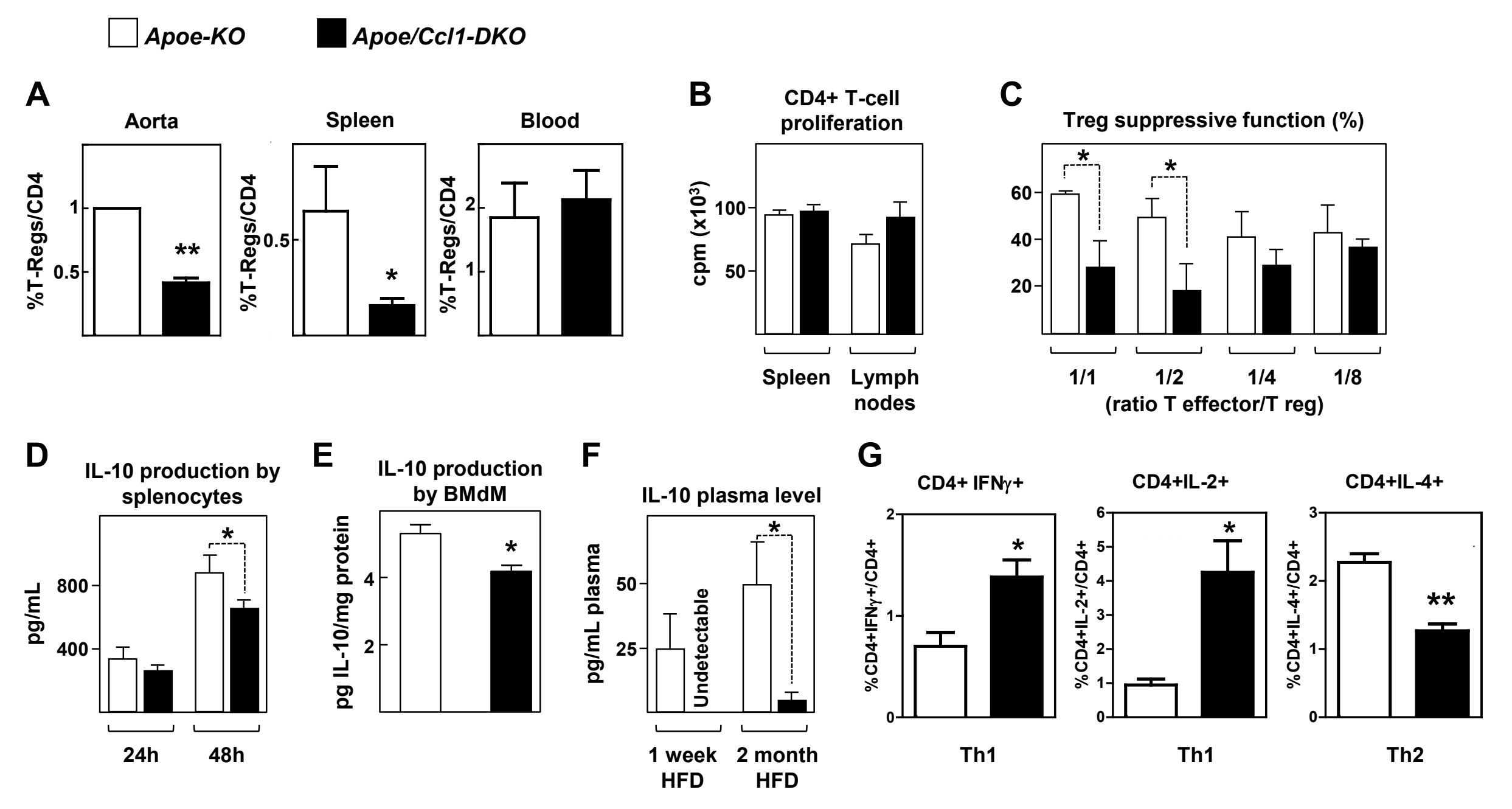


A

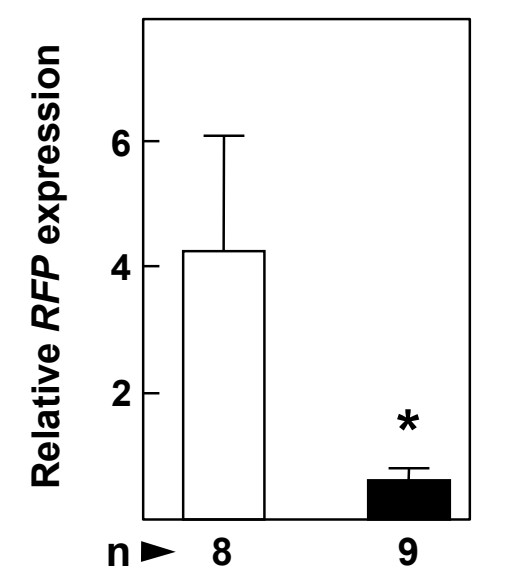

$\square$ Isotype control
B

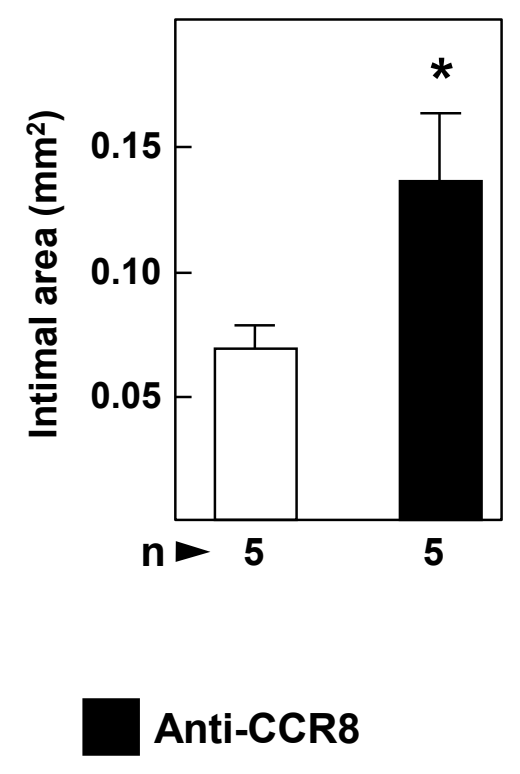

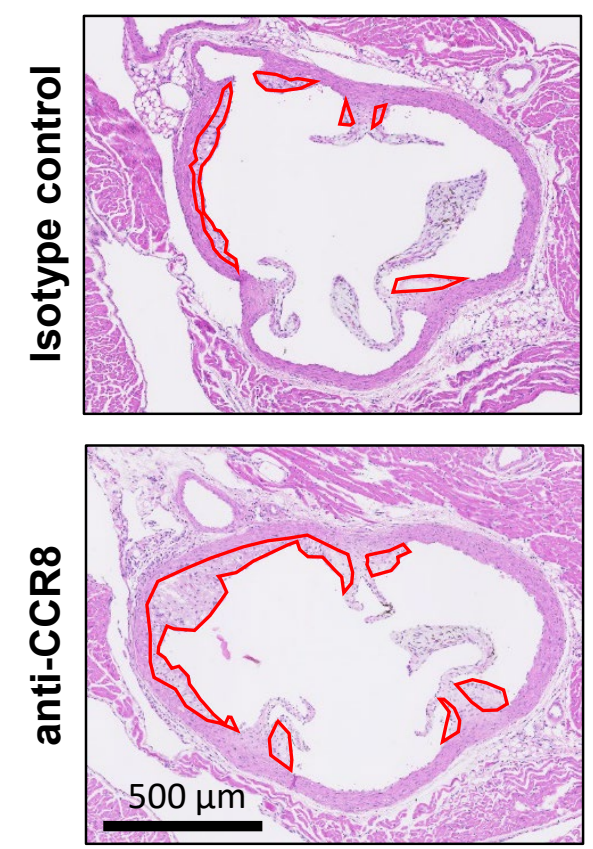

